\title{
Unilateral Lung Hypoplasia - A Rare Presentation in Adulthood
}

\author{
Bharath H. R , Anupam Dutta², Ajit Kumar Pegu³ ${ }^{3}$ Vinod K. H4, Balaji Dhanabalan ${ }^{5}$
}

${ }^{1}$ Department of Medicine, Assam Medical College and Hospital, Dibrugarh, Assam, India. ${ }^{2}$ Department of Medicine, Assam Medical College and Hospital, Dibrugarh, Assam, India. ${ }^{3}$ Department of Medicine, Assam Medical College and Hospital, Dibrugarh, Assam, India. ${ }^{4}$ Department of Medicine, Assam Medical College and Hospital, Dibrugarh, Assam, India. ${ }^{5}$ Department of Medicine, Assam Medical College and Hospital, Dibrugarh, Assam, India.

\section{INTRODUCTION}

Lung hypoplasia is one of the developmental anomalies of the lung parenchyma, in which there is a decrease in the number and size of airways, alveoli and vessels. Here is a case of 36-year-old female with a history of fever, cough with expectoration, dyspnoea, with past history of similar complaints suggestive of recurrent respiratory infections. Chest $x$ ray revealed homogenous opacity in left chest. HRCT thorax set the diagnosis of left pulmonary hypoplasia with compensatory hyperinflation of right lung. Patient was treated conservatively and was advised follow up. Lung hypoplasia majority of the times diagnosed immediately after birth, it is associated with severe respiratory failure and high mortality rate. There are less severe, unilateral forms in which they usually survive with compensatory hyperinflation of the opposite lung and may not be diagnosed till adulthood. Patients usually does not have any symptoms, but patients may present with symptoms suggestive of chronic bronchitis and recurrent lower respiratory tract infections. HRCT thorax helps to differentiate it from other congenital or acquired conditions. Treatment will be conservative, surgical resection is indicated in cases with severe cystic changes and severe symptoms.

Lung hypoplasia comes under the spectrum of developmental anomalies of lung, which causes incomplete development of lung tissue with decrease in the total number of lung cells, airways and alveoli, which finally leads to reduction in lung size and weight. It may be unilateral or bilateral and can lead to severe respiratory failure and death immediately after birth, which is one of the common causes of perinatal mortality. ${ }^{1}$

The less severe forms of lung hypoplasia can survive and may not be diagnosed till adulthood, many of the times in asymptomatic patients it is detected as an incidental finding on radiological imaging, or while investigating for recurrent respiratory tract infections. HRCT thorax is the diagnostic tool of choice. ${ }^{2}$ Here we present a case report of a 36-year-old female patient, with unilateral pulmonary hypoplasia and history of recurrent respiratory tract infections since last 10 years.
Corresponding Author: Dr. Bharath $H R$ 3rd year $P G T$,

Department of Medicine,

Assam Medical College and Hospital,

Dibrugarh, Assam, India.

E-mail: bharathhramesh@gmail.com

DOI: $10.14260 / \mathrm{jemds} / 2020 / 578$

How to Cite This Article:

Bharath HR, Dutta A, Pegu AK, et al. Unilateral lung hypoplasia - a rare presentation in adulthood. J Evolution Med Dent Sci 2020;9(36):2663-2665, DOI: $10.14260 /$ jemds/2020/578

Submission 07-05-2020,

Peer Review 28-07-2020,

Acceptance 03-08-2020,

Published 07-09-2020.

Copyright (c) 2020 JEMDS. This is an open access article distributed under Creative Commons Attribution License [Attribution 4.0 International (CC BY 4.0)]

\section{PRESENTATION OF CASE}

A 36 year old female, house wife belonging to Indian middle class family who uses firewood for cooking with no comorbidities presented to Assam Medical College and Hospital, Dibrugarh with chief complaints of fever, productive cough, dyspnoea (patient had dyspnoea of mMRC grade 1 constantly over last 10 year, now progressed from mMRC grade 1 to 2) of 8 days duration, with past history of admissions to hospital one to two times in a year for similar complaints. 
On examination patient was febrile (100.6 F), tachypnoeic, with low oxyhaemoglobin saturation and was haemodynamically stable. On inspection, trachea was shifted to left and same was confirmed by palpation which also revealed increased vocal fremitus over left chest. Percussion revealed dull note on left chest. On auscultation, air entry was decreased in left infra axillary, infrascapular area, with amphoric type of bronchial breath sound and crepitation was noted in left infraclavicular, mammary, axillary, interscapular area.

\section{CLINICAL DIAGNOSIS}

Collapse with Consolidation of Left Lung

\section{DISCUSSION OF MANAGEMENT}

With provisional diagnosis of, patient was started on antibiotics according to the institutional protocol. Blood parameters showed leukocytosis and increased inflammatory markers.
Chest X-Ray (Figure 1) showed homogenous opacity, mediastinal shift and crowding of ribs on left side. Later HRCT thorax (Figure 2) was done which reported as "minimal lung tissue on left side with compensatory hyperinflation of contralateral lung as evidenced by retro sternal herniation with mediastinal shifting to left side. Left bronchus is not visualized; features suggestive of left side lung hypoplasia". ECG and Echocardiography was done to rule out cardiac condition and USG whole abdomen look for any other associated abnormalities which were within normal limits.

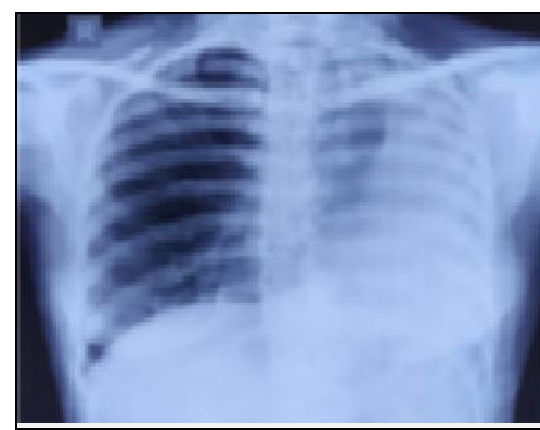

Figure 1. Chest X-Ray PA View

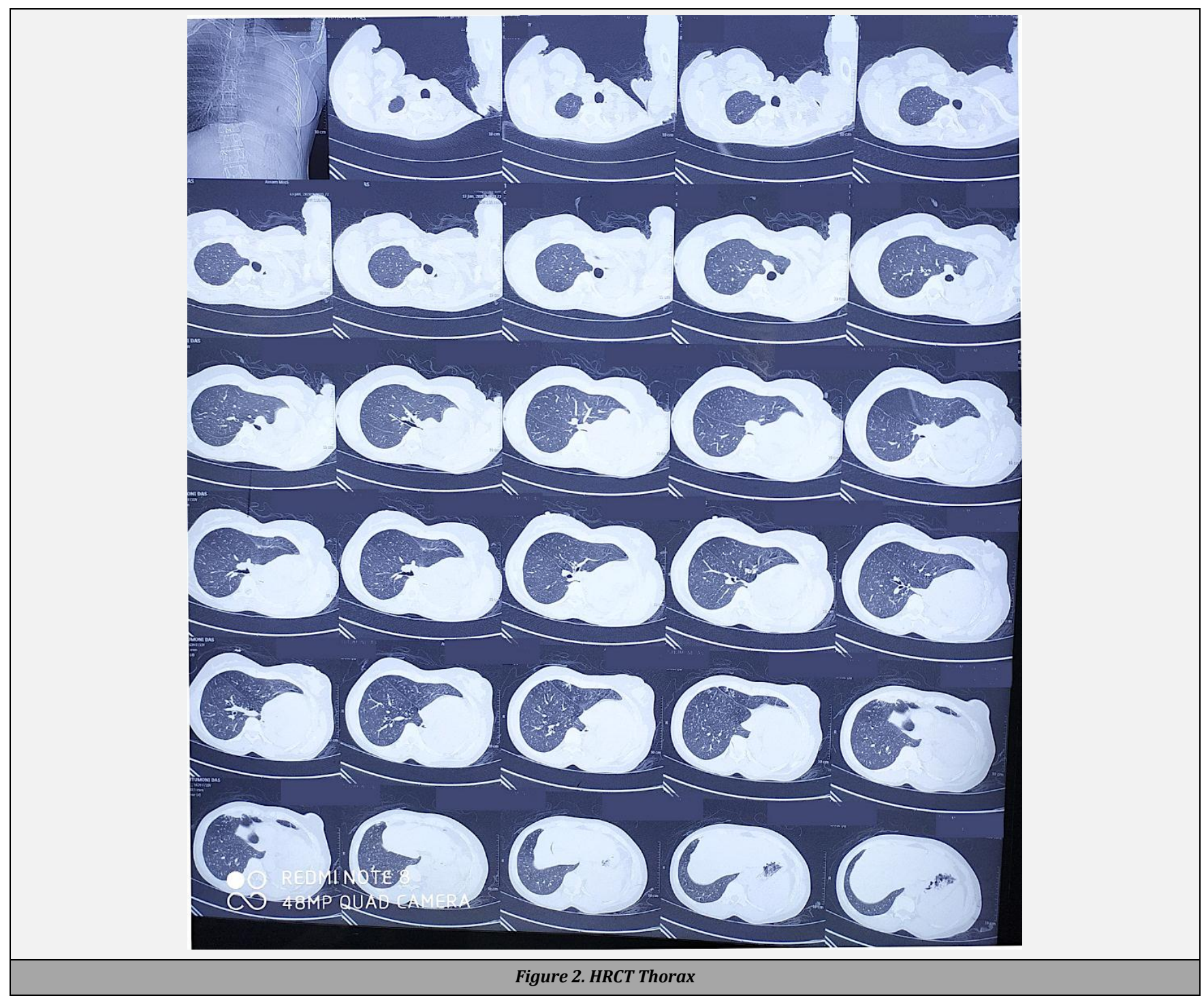




\section{DISCUSSION}

Development of the bronchial tree usually starts at about $26^{\text {th }}$ to $31^{\text {st }}$ day of gestation. The congenital anomalies of the lung arising from $4^{\text {th }}$ to $24^{\text {th }}$ week of gestation may cause functional damage and manifests in paediatric age group usually and can also be seen in adults 3 rarely.

\section{Boyden Classification4 ${ }^{4}$ of Developmental Anomalies of Lung}

1. Pulmonary Agenesis: Structures absent are carina, main bronchi, lung parenchyma, and vessels.

2. Pulmonary Aplasia: Carina and a pouch-like, blind-ending of the main bronchus are present.

3. Pulmonary Hypoplasia: All normal pulmonary tissues are present, but with underdevelopment to various extent.

Incidence of lung hypoplasia is about 1 in 15,000 live births without gender predilection. Patients with lung hypoplasia has decreased weight of the lung, lesser generations of airways, and decreased development of the corresponding pulmonary arteries. There is delay in epithelial differentiation and there is deficiency of surfactant as well. There is a mediastinal shift to the side of lung hypoplasia and associated with compensatory herniation of the normal lung.

Lung hypoplasia are classified as primary (idiopathic) and secondary based on aetiology and unilateral and bilateral based on the involvement of lung.

\section{Unilateral Pulmonary Hypoplasia}

- $\quad$ Conditions that decrease intrathoracic space. ${ }^{5}$

- Congenital diaphragmatic hernia.

- Ipsilateral congenital vascular anomalies.

\section{Bilateral Hypoplasia}

- Oligohydramnios (renal tract disorders or by amniotic fluid leak). ${ }^{6}$

- Premature rupture of the membranes.

- Maternal treatment with ACE inhibitors. ${ }^{7}$

Clinical course of the patient depends upon degree of involvement of the lung. It may be ranging from respiratory failure that requires prolonged mechanical ventilation and ending up with early death (fatal form), to respiratory insufficiency forms associated with pulmonary hypertension, bronchopulmonary dysplasia or subacute lung disease, to mild symptoms (non-fatal form). ${ }^{8}$ As with our patient, some of the patients have a silent childhood, the disease being manifested only at adulthood as lower respiratory tract infection, due to pooling of bronchial secretions, secondary bacterial infection and spillage of the infected secretions into the uninvolved lung. ${ }^{9}$
The treatment in adults is conservative and consisting of treating the respiratory infections, prophylactic vaccinations. In few patients, surgical treatment may be indicated in cases with combination of abnormal airway angulation and decreased mucociliary clearance leading to pooling of secretions which leads to recurrent respiratory infections and cystic degeneration of the airways. ${ }^{10}$

\section{CONCLUSIONS}

Lung hypoplasia is a congenital anomaly with various causes usually discovered in neonates and infants. Patient may be asymptomatic or may present with recurrent respiratory tract infections in adulthood. HRCT thorax aids in diagnosis. Treatment is conservative and surgical intervention is required in case of pronounced symptoms.

Financial or Other Competing Interests: None.

\section{REFERENCES}

[1] Laudy JA, Wladimiroff JW. The fetal lung. 2: pulmonary hypoplasia. Ultrasound Obstet Gynecol 2000;16(5):48294.

[2] Comet R, Mirapeix RM, Marín A, et al. Pulmonary hypoplasia in adults: embryology, clinical presentation and diagnostic methods. Our experience and review of the literature. Arch Bronconeumol 1998;34(1):48-51.

[3] Kurkcuoglu IC, Eroglu A, Karaoglanoglu N, et al. Pulmonary hypoplasia in a 52-year-old woman. Ann Thorac Surg 2005;79(2):689-91.

[4] Boyden EA. Developmental anomalies of the lungs. The Am J Surg 1955;89(1):79-89.

[5] Wigglesworth JS, Desai R, Guerrini P. Fetal lung hypoplasia: biochemical and structural variations and their possible significance. Arch Dis Child 1981;56(8):606-15.

[6] Husain AN, Hessel RG. Neonatal pulmonary hypoplasia: an autopsy study of 25 cases. Pediatr Pathol 1993;13(4):475-84.

[7] Shotan A, Widerhorn J, Hurst A, et al. Risks of angiotensinconverting enzyme inhibition during pregnancy: experimental and clinical evidence, potential mechanisms and recommendations for use. Am J Med 1994;96(5):4516.

[8] Sherer DM, Davis JM, Woods JR Jr. Pulmonary hypoplasia: a review. Obstet Gynecol Surv 1990;45(11):792-803.

[9] Roque AS, Burton EM, Boedy RF, et al. Unilateral pulmonary agenesis without mediastinal displacement. South Med J 1997;90(3):335-7.

[10] Thomas RJ, Lathif HC, Sen S, et al. Varied presentations of unilateral lung hypoplasia and agenesis: a report of four cases. Pediatr Surg Inter 1998;14(1-2):94-5. 